Jean Pirotte, dir., Résistances à l'évangélisation. Interprétations historiques et enjeux théologiques

Paris, Karthala, coll. « Mémoires d'Église », 2004, 298 p.

\title{
Brigitte Bleuzen
}

\section{(2) OpenEdition}

\section{Journals}

Édition électronique

URL : http://journals.openedition.org/assr/4022

DOI : $10.4000 /$ assr. 4022

ISSN : $1777-5825$

Éditeur

Éditions de l'EHESS

Édition imprimée

Date de publication : 1 décembre 2006

Pagination : 115-283

ISBN : 2-7132-2124-2

ISSN : 0335-5985

Référence électronique

Brigitte Bleuzen, « Jean Pirotte, dir., Résistances à l'évangélisation. Interprétations historiques et enjeux théologiques », Archives de sciences sociales des religions [En ligne], 136 | octobre - décembre 2006, document 136-87, mis en ligne le 14 février 2007, consulté le 10 décembre 2020. URL : http:// journals.openedition.org/assr/4022 ; DOI : https://doi.org/10.4000/assr.4022

Ce document a été généré automatiquement le 10 décembre 2020.

(C) Archives de sciences sociales des religions 


\title{
Jean Pirotte, dir., Résistances à l'évangélisation. Interprétations historiques et enjeux théologiques
}

\author{
Paris, Karthala, coll. « Mémoires d'Église », 2004, 298 p.
}

\section{Brigitte Bleuzen}

1 L'ouvrage est issu d'une journée "d'hommage et de réflexion », organisée à LouvainLa-Neuve le 7 mai 2003, à l'occasion de l'accession à l'éméritat de Maurice Cheza, théologien, et Claude Soetens, historien. En fin d'ouvrage, deux contributions donnent un aperçu à la fois des carrières, des thèmes de recherche investis et des publications des deux auteurs à l'honneur. L'historien Jean Pirotte, qui dirige l'ouvrage, situe l'acte de résistance comme "une marque du vivant» (p. 8) par laquelle l'être humain se révèle. Le Petit Robert définit « résistance » comme "l'action par laquelle on essaie de rendre sans effet une action dirigée contre soi ». L'approche est volontairement pluridisciplinaire : historiens, anthropologues et psychologues étudient les modalités de résistance à l'évangélisation dans les "pays de mission" ad extra et ad intra. Le premier volet de la réflexion aborde la question sous l'angle méthodologique, le second propose sept études de cas.

2 Jean Pirotte ouvre la marche en proposant trois modèles de "rencontre " du christianisme avec d'autres cultures. Le «modèle de la diffusion» (p. 15) s'avère être possible dans des sociétés fermées qui recherchent de nouveaux genres de vie. Le christianisme joue alors un rôle de catalyseur auprès de groupes aspirant à une certaine ouverture. Le " modèle de l'importation » impose à terme une uniformisation " sur la base de critères prétendument universels, mais en fait étrangers à la culture qui les reçoit» (p. 18). Le «modèle de l'inculturation " pour les catholiques et le «modèle de la contextualisation " pour les protestants stipulent que la vie chrétienne s'incarne dans la diversité des cultures. Il s'agit pour les missionnaires de repérer, dans les valeurs humaines des peuples non chrétiens, ce qu'elles contiennent « de commun ou de compatible avec l'évangile ». La théologie des «pierres d'attente » est issue de cette conception. Considérée comme ethnocentrique, elle fut contestée car les valeurs 
n'étaient vues que du côté des missionnaires. D'autre part, les « pays de mission » ont revendiqué le droit de traduire la foi dans leur culture et d'organiser la vie ecclésiale. Jean Pirotte aborde ensuite toute la palette des stratégies missionnaires entre l'attention aux plus jeunes, la mise à l'écart des convertis, la conversion par le sommet, les services attractifs offerts aux populations sur le plan de l'éducation et de la santé, etc. Ces stratégies d'évangélisation inscrites tantôt dans un discours de combat, tantôt dans une négation des cultures provoquent, en retour, des résistances qui prennent la forme de rejet violent, de résistance passive, d'acceptation de façade ou encore de syncrétisme par la poursuite des pratiques anciennes. La ruse, par la conversion feinte, est fréquente. Il reste que les missionnaires se heurtent à « l'imperméabilité de certains peuples trop éloignés, par leur façon de vivre, du modèle chrétien occidental » comme les sociétés de chasse et de cueillette et les pays ayant développé « leur propre religion universaliste ou des philosophies de type réflexif » (p. 35) comme la Chine, le Japon et l'Inde.

3 La situation dans les sociétés occidentales sécularisées est spécifique. Après la Seconde Guerre mondiale, des populations en nombre croissant se détachent de la pratique chrétienne ou rejettent toute foi. Et, parmi les chrétiens, l'usage de la raison critique modifie les rapports de hiérarchie au profit d'une subjectivation croissante. Cependant, selon José Reding, théologien, les termes du débat se déplacent, à la fois sur un «non savoir » quant à l'existence de Dieu et un «non savoir » quant à l'inexistence de Dieu (p.111). La marge de manœuvre est étroite pour l'évangélisation qui désire désormais s'inscrire dans « une nouvelle complicité » avec la culture de la société sécularisée et individualisée et inédite en mettant en valeur l'argument d'une « réelle autonomisation et réjouissance humaine » (p. 127-128).

4 Michaël Singleton, anthropologue, offre à notre réflexion une " anthropo-logique du refus» (p. 88) en partant du principe que si une affirmation ne peut jamais être absolue, tout refus ne saurait être que relatif (p. 92-93). Cette posture s'avère tout simplement impossible dans des contextes d'intransigeance où la vérité est défendue comme la Vérité absolue. Comment alors respecter le oui de l'un et le non de l'autre, en d'autres termes «le relativement absolu des deux»? Michaël Singleton prend appui sur la notion de « différend » de Jean-François Lyotard pour conclure que «l'impossible identité à l'identique rend la différence non seulement inéluctable, mais vitale " (p.97). Ce raisonnement pourrait être mis en perspective dans le cadre du dialogue interreligieux étudié par Anne-Sophie Lamine qui propose de concevoir que «la reconnaissance de l'autre et la possibilité de collaborer avec lui sont liées de manière réciproque à la vérité ou à la validité qu'on accorde à sa voie religieuse. » La validité englobe trois dimensions: théologique, éthique et celle de la sincérité (ou de l'authenticité). Et, de ces trois dimensions de la vérité, découlent différentes attitudes dans les religions interreligieuses (Anne-Sophie Lamine, La cohabitation des Dieux, Paris, PUF, 2004, p. 278).

5 Les sept études de cas d'évangélisation opérée par des chrétiens (protestants et catholiques) offrent un éventail de contextes à la fois historiques, culturels et religieux. La résistance des musulmans à l'évangélisation est évoquée par Oissila Saaidia, «L'évangélisation des musulmans, mission impossible?». Puis, celle des Africains est analysée à travers trois dossiers : Jean-François Zorn, « La fin de l'âge d'or de la Mission protestante au Lesotho au milieu du XIx ${ }^{e}$ siècle, diagnostic d'un échec et d'une reprise », Jean-Marc Ela, « Mémoire d'insoumission et résistances à l'évangélisation : un défi à la 
théologie africaine?», Sabine Kakunga Madilu, «Résistances à l'évangélisation, le point de vue d'une femme africaine ». Ensuite, est rappelée la résistance des Indiens : Olivier Servais, « Anishinaabeg et missionnaires jésuites dans la région des Grands Lacs nord-américains, 1842-1909. Stratégies de conversion et résistances indiennes ». Enfin, la résistance des populations asiatiques est abordée par deux contributions: JeanPierre Duteil, «L'opposition aux missionnaires catholiques en Extrême-Orient : Japon, Chine et Dai-Viêt aux $\mathrm{XVI}^{\mathrm{e}}$ et $\mathrm{xvIII}{ }^{\mathrm{e}}$ siècles " et Claude Prudhomme, "Résistances à l'évangélisation et stratégies missionnaires romaines : l'exemple de la Chine ( $\mathrm{xIx}^{\mathrm{e}}$ et $\mathrm{xx}^{\mathrm{e}}$ siècles) ». Parmi les cas traités, l'aire culturelle asiatique a particulièrement retenu mon attention.

En Chine, le confucianisme officiel - celui de la cour et des lettrés - s'oppose au christianisme. Les jésuites tentent, au XVII ${ }^{\mathrm{e}}$ siècle, de trouver une voie de conciliation en considérant notamment les offrandes aux morts comme un rite civique sans signification religieuse. Ils seront condamnés par Rome qui juge la position des jésuites trop favorable à la civilisation chinoise. La « querelle des rites » (1630-1742) laissera des traces et sera suivie de la "controverse anti-confucéenne ». Prolongeant les recherches de Jacques Gernet (Chine et christianisme, action et réaction, Paris, Gallimard, 1982), Claude Prudhomme se demande si l'absence d'écho des efforts d'évangélisation en Chine par les Occidentaux, n'est pas le lieu d'un «malentendu plus profond » qui s'expliquerait par un désintérêt des Chinois pour la religion catholique. $A u x^{e}$ siècle, les rêves de nouvelle chrétienté ont été abandonnés pour une proposition de la foi et l'acceptation d'être minoritaire. Aujourd'hui, l'Église catholique chinoise reste d'une part en marge de la société chinoise et, d'autre part, se situe en marge de l'autorité du Vatican. En Asie, de façon générale, les missionnaires se heurteront non seulement au confucianisme, au bouddhisme et au taoïsme mais aussi au culte des ancêtres lié au culte des esprits qui ne peuvent être réduits aux «superstitions» dont parlaient les religieux catholiques (Jean-Pierre Duteil, p. 207). Le cas du Vietnam est particulier : en effet, si le Vietnam est bouddhiste mahayaniste, la doctrine officielle reste confucianiste. Cependant, le catholicisme y aura plus de succès que dans les pays bouddhistes hinayanistes comme le Cambodge et la Thaillande. On pourra lire avec profit, la recherche historique comparative, pourtant non citée, menée par Alain Forest, Les missionnaires au Tonkin et au Siam XVII ${ }^{e}$-XVIII ${ }^{e}$ siècles, Paris, L'Harmattan, 1998.

7 L'étude des échecs d'évangélisation est riche d'enseignement sur le non respect de l'altérité, la question et la place de la vérité pour les religions. L'échec dans les pays musulmans initia de nouveaux modes de présence comme l'annonce «muette » de Charles de Foucauld. Mais surtout, à partir des années 1960 et en dépit des stratégies d'instrumentalisation opérées par les protagonistes à des fins de légitimité, le dialogue s'enclenche dans les relations islamo-chrétiennes (0. Saaidia, p. 271). L'ouvrage pose des questions essentielles non seulement pour l'histoire mais aussi pour l'actualité. Récemment, des pays africains majoritairement chrétiens, ont vécu des tragédies comme le génocide de 1994 au Rwanda qui opposa Tutsis et Hutus; ces évènements obligent à reconsidérer les termes du débat. Les explications invoquées par Rome (responsabilité des dirigeants africains, «fausse christianisation », etc.), ne constituent pas, selon Claude Prudhomme, «des réponses sur le fond» (p. 231-232). Cet ouvrage pourrait trouver des prolongements avec l'étude d'autres aires culturelles comme l'Amérique centrale et latine, des recherches complémentaires sur les méthodes usitées 
par les évangélistes et pentecôtistes et enfin des analyses des effets de la mondialisation sur l'évangélisation.

8 Ce thème de la résistance est incontournable pour qui s'intéresse au dialogue interculturel et interreligieux où le rapport à l'altérité reste complexe, tant la prétention à l'universel est forte. 